This item was submitted to Loughborough's Research Repository by the author.

Items in Figshare are protected by copyright, with all rights reserved, unless otherwise indicated.

\title{
A user centred design evaluation of the potential benefits of advanced wireless sensor networks for fire-in-tunnel emergency response
}

\section{PLEASE CITE THE PUBLISHED VERSION}

http://dx.doi.org/10.1016/j.firesaf.2013.11.007

\section{PUBLISHER}

(C) Elsevier Ltd.

\section{VERSION}

AM (Accepted Manuscript)

\section{PUBLISHER STATEMENT}

This work is made available according to the conditions of the Creative Commons Attribution-NonCommercialNoDerivatives 4.0 International (CC BY-NC-ND 4.0) licence. Full details of this licence are available at: https://creativecommons.org/licenses/by-nc-nd/4.0/

\section{LICENCE}

CC BY-NC-ND 4.0

\section{REPOSITORY RECORD}

May, Andrew, Val Mitchell, and John Piper. 2019. "A User Centred Design Evaluation of the Potential Benefits of Advanced Wireless Sensor Networks for Fire-in-tunnel Emergency Response". figshare. https://hdl.handle.net/2134/18869. 


\title{
A user centred design evaluation of the potential benefits of advanced wireless sensor networks for fire-in-tunnel emergency response
}

\author{
Andrew Maya ${ }^{\mathrm{a}}$, Val Mitchell ${ }^{\mathrm{b}}$, John Piper $^{\mathrm{c}}$ \\ a [corresponding author] a.j.may@lboro.ac.uk, +44 1509 226906, Design School, Loughborough \\ University, Loughborough, LE11 3TU, UK \\ ${ }^{\mathrm{b}}$ Design School, Loughborough University, Loughborough, LE11 3TU, UK \\ ${ }^{c}$ Kodak Ltd. Headstone Drive Harrow Middlesex HA1 4TY, UK, now contactable at \\ johnpiperstudio@gmail.com
}

\begin{abstract}
This study aimed to assess, from an end-user perspective, the potential role of reconfigurable wireless networks in responding to a fire-in-tunnel incident. The study was based on a multi-media, scenario-based simulation of an incident, and assessment of the benefits and drawbacks of the new technology by subject matter experts in relation to their operational goals, with particular emphasis on support for situation awareness. Advanced wireless networks were shown to have considerable potential for improving the effectiveness, efficiency and confidence of emergency responders at various phases in a fire-in-tunnel incident, due to access to more accurate, complete and reliable information. A key requirement was to ensure that new technologies provided the right information, not just more information, at the point of need.
\end{abstract}

\section{Keywords}

User centred design; simulation; tunnel fire; emergency response; wireless sensor network 


\section{Introduction}

\subsection{Background}

Situation awareness (SA) is recognised as a key requirement for effective decision making in emergency response [1]. In certain types of incident, such as a fire in a tunnel, it is difficult for emergency responders to develop and maintain SA due to dynamic nature of traffic, the lack of line of sight to the incident, the obscuration of the scene (and CCTV) by smoke, and potential damage to power, communication and monitoring networks. SA has been identified as a key issue in major incidents such as the World Trade Centre disaster [2]. Limitations in the information available at an emergency - and hence difficulties in developing and maintaining SA - have been shown to lead directly to decision making failures by the fire and rescue service [3].

Although a range of sensors are available [4], traditional wired networks have drawbacks in terms of installation time, overall cost and flexibility in tunnel environments [5]. Emerging technologies, such as advanced wireless sensor networks (WSNs), have the potential to enhance the information environment in order to increase the SA during an incident, and help support decision making and other operational objectives during emergency response [6], [7]. A WSN is defined as a group of specialized transducers with a communication infrastructure that can monitor and record data at diverse locations [8]. Sha et al. [9] argue that as long as specific research challenges - including: realtime self-organisation, fault tolerant routing, and realtime and mobile localisation - can be addressed, WSNs are a very promising technology for fire rescue applications, and there has been increasing interest in the use of WSN for fire detection and response [5].

Although new technologies offer potential for improved emergency response, a challenge is how to assess the benefits they could provide. IT-based innovation to support emergency response has been slow to be adopted by the emergency services [10], [11], and end user involvement of emergency responders in the design of supporting technologies has historically been too sporadic [12]. It is beneficial to assess their potential impact at an early stage, before such developed systems actually exist, since this helps identify, with relatively low cost and effort, where the relative advantage and barriers occur, for enhancing emergency response. Despite the promise of new technologies, there has been concern that technology centred approaches to systems design focus on data provision rather than operational impact [13], [14]. Carver and Turoff [15] call for a user-centred approach to the design of emergency management information systems, with an emphasis on user requirements. This perspective starts with the emergency responders, their responsibilities and operational goals, and their information needs. It focuses explicitly on the enabling properties of new technology, and 
the benefit that is provided to the end users. Early evaluation of prototypes is a key component of such approaches [16].

\subsection{Aims}

The main aim of the study reported in the article was to explore the extent to which advanced WSNs can potentially enhance emergency response in relation to key operational objectives during a firein-tunnel incident. This article uses a PACT (people, activities, context, technology) [17] framework to design a simulation, that demonstrated the functional capabilities that advanced WSNs could provide during a fire-in-tunnel incident. A secondary aim of this article is to demonstrate how the potential usefulness of new technologies can be demonstrated and evaluated from a user centred perspective.

\section{Literature}

\subsection{The need for situation awareness (SA)}

SA is key to decision making in complex emergency response [1], [18], [19]. It is described by Endsley [20] as the 'perception of the elements in the environment within a volume of time and space, the comprehension of their meaning and the projection of their status in the near future', comprising Level 1 (identification of elements in the environment), Level 2 (interpretation of their meaning), and Level 3 (their future projection).

In essence, SA is the extent to which the perception of an environment by an individual is an accurate reflection of reality. In almost every time-critical and complex domain SA plays a key role in decision making and effective performance [21] and it has been shown that the faster incident commanders analyse and act on key information, the more effective their response will be [22]. Although high SA does not always lead to better decisions [23], it has been recognised that many shortcomings in disaster response operations are due to poor decisions made by first responders due to a lack of SA [24]. The official NIST report into the emergency response operations at the World Trade Centre disaster [2] concluded that 'situational awareness was an overriding issue with all emergency responders during the WTC operations', and that either too much, or too little information on the situation 'prevented responders from having adequate, accurate, and timely information for decisions that were critical to operations and may have been critical to life safety... ‘ 


\subsection{Properties of emerging wireless sensor networks}

Advanced WSNs have several advantages over fixed networks within an emergency response scenario in a tunnel [5]. They are more easily reconfigurable and scaleable, and the network can be made more flexible due to the lack of requirement for hardwired connections. Their primary disadvantages are increased cost, being fault prone [25], and limitations in battery life. Advances in WSNs mean that data networks can now display a number of properties which mean they are better able to support emergency response to a fire-in-tunnel scenario. These properties can be capitalised on within both the preparedness and response phases of emergency response, as outlined in Table 1 below.

\begin{tabular}{ll}
\hline Network property & $\begin{array}{l}\text { Implication in relation to a fire-in-tunnel } \\
\text { incident }\end{array}$ \\
\hline Reconfigurable & $\begin{array}{l}\text { The network can be reconfigured to perform new } \\
\text { tasks or new ways of performing existing tasks }\end{array}$ \\
Nelf-healing & $\begin{array}{l}\text { Network can continue to function if damage to it } \\
\text { occurs, at the onset of, or during an incident } \\
\text { The size of the network can be scaled up and } \\
\text { down as sensors join or leave, to supplement or } \\
\text { maintain data network capability }\end{array}$ \\
Heterogeneous & $\begin{array}{l}\text { Networks can connect different operating } \\
\text { systems together as well as connect fixed and } \\
\text { mobile sensors }\end{array}$ \\
\hline
\end{tabular}

Table 1. Properties of advanced wireless sensor networks

Ahmed and Sugianto [26] investigated the potential benefits of adopting RFID within emergency response, and highlighted the need for 'acquiring robust technologies which can work consistently in unfavourable working conditions'. Other examples of the proposed applications of advanced WSNs in emergency response include: reconfigurable architectures for heterogeneous embedded systems [27]; adhoc networks for situation management [19]; monitoring location and vital signs of firefighters [28]; help with evacuation [29]; use of robots to introduce new sensors into a network [30].

These contributions highlight the technical capabilities of advanced WSNs, and particularly those that are reconfigurable. However the literature lacks investigation of the potential impact of WSNs on the wider operational capabilities of first responders, and this early (and therefore low cost) 
evaluation of the effectiveness of future technologies within emergency response contexts is illustrated in this article.

\section{Methodology}

\subsection{Theoretical perspectives}

This article takes a user-centred [31], rather than technological perspective and places the emergency responder at the focus of interest. A user-centred design (UCD) perspective is increasingly being used within multidisciplinary design and research teams, in order to establish the impact of new technologies. With user-centred systems design a key principle is early end user evaluation of prototypes which are used to visualise and evaluate ideas [16].

A value-added approach [32], [33] was used to theoretically compare the information environments provided by fixed networks and the potential capabilities of a WSN . The potential benefits of each during emergency response is shown in Figure 1, representing the difference in outcomes that can result when a limited or degrading information environment is maintained or supplemented by a WSN.

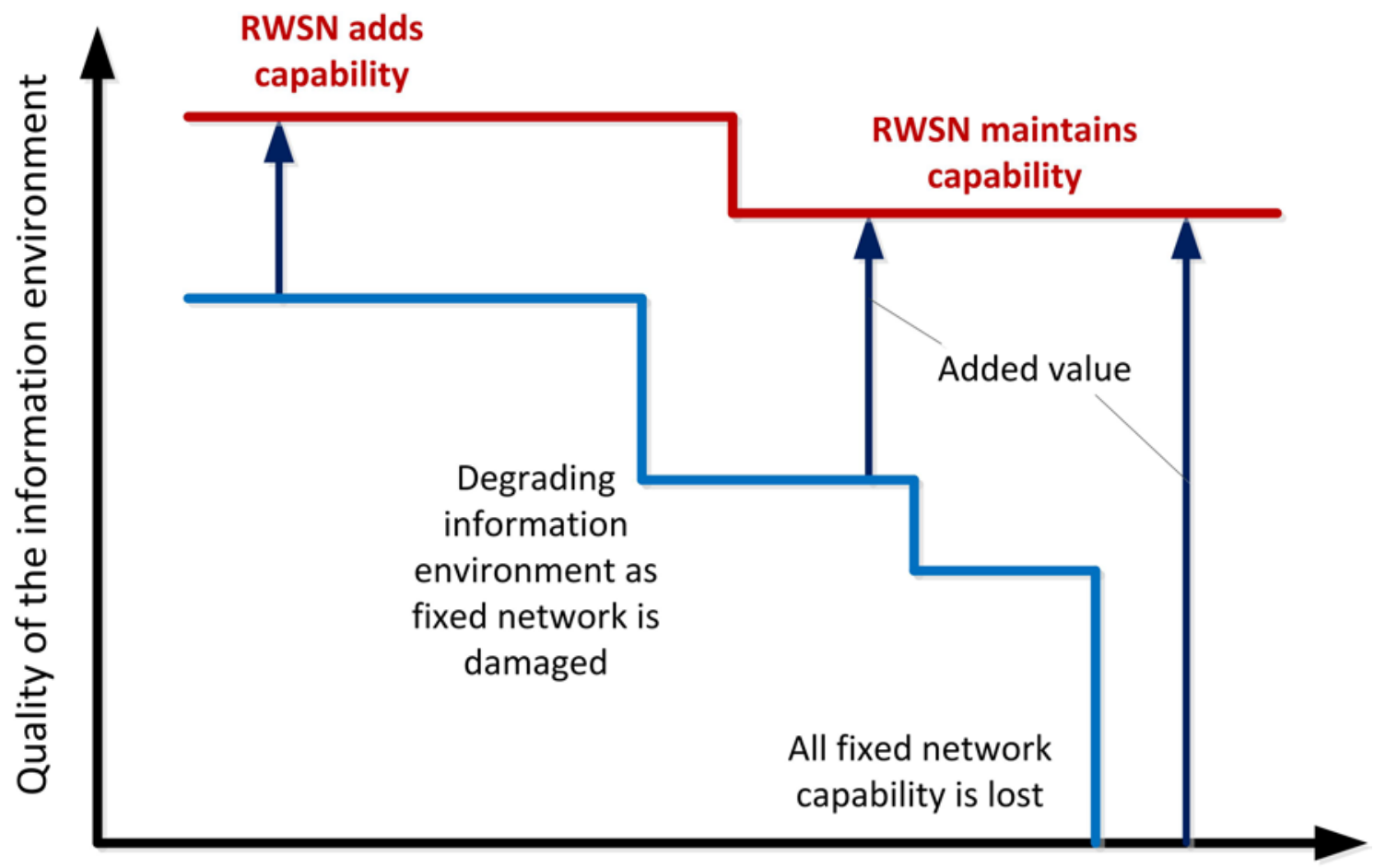

Elapsed time

Figure 1. The 'added value' of an enhanced information environment 
A goal-directed approach was used to establish the link between individuals, the operational objectives at different stages within a fire-in-tunnel scenario, and their information requirements. Within human-computer interaction (HCI), task analysis has been used for many years to help understand the activities that individuals undertake and their motivations for doing so [34]. More recently, new frameworks have been developed that make a more explicit link between user goals and information needs [35], [36].

The final theoretical consideration was the nature of the outcome metrics that would be used to compare different technology-enabled scenarios. A usability evaluation framework was used where usability is defined as 'the extent to which a product can be used by specified users to achieve specified goals with effectiveness, efficiency and satisfaction in a specified context of use' [37]. Usability has been established within the HCI literature for many years [38], and is particularly suited to work-based IT implementation where tasks and goals are relatively easy to define, and where the time or other resources needed to undertake those tasks are important.

The usability standard [37] highlights the importance of ensuring that the correct individuals take part in evaluations, the need for a realistic environment, and clear definition of important goals or operational objectives. The focus on goals is also consistent with SA being defined according to the goals and decision requirements for a particular job [39], [40]. The main operational objectives were defined for the individuals involved in each of the scenario stages, and the usability of the WSN was assessed in relation to each of these objectives (see Table 3). The rationale for the scenarios, and their design, are described below.

\subsection{Scenario design and validation}

Scenario-based approaches have been used for over 20 years to envision the end user within a realistic context of use during system design. Their key strength is that they define how an end-user 'experiences' emerging ICT within a situated context of use. Scenarios make use of technology rather than technology itself the object of design [41], and are an established within UCD to explore the impact upon end user performance of novel or emerging technologies..

There is no one 'scenario methodology'. Scenarios themselves can take many forms - they can be textual narratives, storyboards, video mockups, scripted prototypes, or physical representations. However they are designed, 'the defining property of a scenario is that it projects a concrete description of an activity that the user engages in when performing a specific task, a description sufficiently detailed so that design implications can be inferred and reasoned about' [42], p3-4. 
Scenarios can also be used at any stage of the systems development lifecycle [43], shown below in Figure 2.

\begin{tabular}{|l|l|l|l|l|l|l|}
\hline $\begin{array}{l}\text { Requirements } \\
\text { Discovery }\end{array}$ & $\begin{array}{l}\text { Requirements } \\
\text { Validation }\end{array}$ & $\begin{array}{l}\text { System } \\
\text { Specification }\end{array}$ & System Design & $\begin{array}{l}\text { Coding, First } \\
\text { of Class }\end{array}$ & $\begin{array}{l}\text { Integration \& } \\
\text { Testing }\end{array}$ & $\begin{array}{l}\text { Operations \& } \\
\text { Maintenance }\end{array}$ \\
\hline
\end{tabular}

Figure 2. The use of scenarios at exploratory stages in the systems development lifecycle [43]

In this study they are employed at the requirements discovery/validation phases. More specifically, this work is based on the 'alternative world' view [44], where a scenario 'describes a more or less static picture of an imagined future (business) situation, often parameterised in a simulation model to enable system options to be explored and compared’.

This study methodology incorporated the PACT (people, activities, context, technology) framework [17]. Wireless sensor network technical specialists (technology) worked with fire emergency experts (context) to define how wireless sensor technologies would be integrated into a timeline of an 'alternative world' view based on a fire-in-tunnel incident. Fire-in-tunnel was chosen because it presented particular challenges described above. Based on the typical progression of a fire in tunnel incident, specific activities were identified that needed to be performed (e.g. initial monitoring of traffic), together with the people responsible.

The simulation comprised six sequential stages within a fire-in-tunnel response (Table 2). Each of the stages in the scenario was designed to demonstrate a specific capability that a WSN could provide based on the properties shown in Table 1 (for example the ability to self-heal by switching from wired to wireless data transmission).

\begin{tabular}{lll}
\hline Scenario stage & WSN concept & $\begin{array}{l}\text { Specific capability } \\
\text { demonstrated }\end{array}$ \\
\hline $\begin{array}{l}\text { 1. Normal tunnel operation } \\
\text { Auto-configuration of an } \\
\text { adhoc sensor network }\end{array}$ & $\begin{array}{l}\text { Enables the fixed sensor network } \\
\text { to locate vehicles entering the } \\
\text { tunnel, and presence of any } \\
\text { hazardous cargos }\end{array}$ \\
$\begin{array}{l}\text { Enables passing of data between } \\
\text { cars and tunnel network }\end{array}$ \\
$\begin{array}{l}\text { An incident occurs within } \\
\text { the tunnel and fire service } \\
\text { alerted }\end{array}$ & Date fusion & $\begin{array}{l}\text { Enables the Tunnel Operator to } \\
\text { judge whether an incident has } \\
\text { actually occurred, by minimising } \\
\text { false alarms and missed alarms }\end{array}$ \\
\hline
\end{tabular}


3. Fire crews are sent current dynamic incident information whilst en-route

4. Fire crews arrive; selfhealing of network by switching to wireless data transmission

5. Fire damage increases; selfhealing of network by rerouting of wireless sensor data

6. Restoration of connectivity using self-positioning robot mounted sensors
High bandwidth connection between the Tunnel Control network and the Fire Command Network as the primary channel for communication

Automatic reconfiguration of the sensor network to enable a switch from wired to wireless data transmission

Automatic reconfiguration of the sensor network to enable a multi-hop ${ }^{1}$ re-routing of data

Network configuration and reconfiguration
Provides the actual situation map, can forward the CCTV frames, and provides access to historical data

Self-healing - enables the heat sensors in the tunnel to continue to send data back to the Tunnel Control Room, after damage to the fixed network has occurred

Self-healing - enables continued wireless transmission of data to the Tunnel Control Room, after damage to sensors has occurred Self-healing - enables continued wireless transmission of data to the Tunnel Control Room

\section{Table 2. WSN concepts incorporated in the simulation}

Having defined the scenario above, operational objectives at each stage in the incident were identified from previous research and field visits to UK and European fire commanders and tunnel operators. The scenario was then validated through meetings with subject matter experts; this resulted in no significant changes. As a final step, a data collection template was produced for each stage of the scenario. This included a brief description of the stage, a definition of the operational objectives for that stage, and a set of rating scales. Using the elements within the PACT framework [17] this enabled the people to undertake specific activities within a context of use, supported by emerging technology, - and to assess their projected level of performance against key operational objectives.

To enable the value-added comparison described in Figure 1, two versions of each scenario stage were created. These represented (1) the information environment typically present in existing road tunnels, (including the presence of a wired sensor network), and (2) the information which could be made available to emergency responders using WSNs. Each stage within the scenario comprised a narrative which described the events taking place, a large multi-screen audio-visual simulation, and multi-screen incident display presenting information to the emergency responder.

\footnotetext{
${ }^{1}$ Multi-hop is a means of enabling data to 'hop' from node to node within a multimode date network, allowing wireless transmission with reduced power consumption [56]
} 


\subsection{Simulation design}

The simulation was based in a large usability lab, shown in Figure 3. It was designed to replicate the main sources of information present at a fire-in-tunnel incident. The main display was created by three overhead high lumen data projectors which provided a seamless projected image of $8 \mathrm{~m} \times 2 \mathrm{~m}$ onto one wall at an overall resolution of 5760x1080 pixels. This displayed a simulation of a tunnel schematic and CCTV images, or a view of the emergency site, depending on the stage of the simulation. A control desk was set up with three interlinked monitors that provided a dynamic simulation of traffic flow and data sensor readings. An additional monitor on the desk simulated a selectable CCTV image. On the side wall, a flat screen display simulated an exterior scene. A surround sound audio system was used to play an audio backdrop to increase the realism of the simulation. To the rear of the lab was a control zone where the presentation of scenes within the simulation could be controlled.

Figure 3 shows the overall setup of the usability lab. The visual displays within the usability lab were based on those in the Elbe Tunnel and the Øresund Tunnel control rooms which were visited as part of the fieldwork, shown in Figure 4. Figures 5-7 show more detailed views of the simulation.

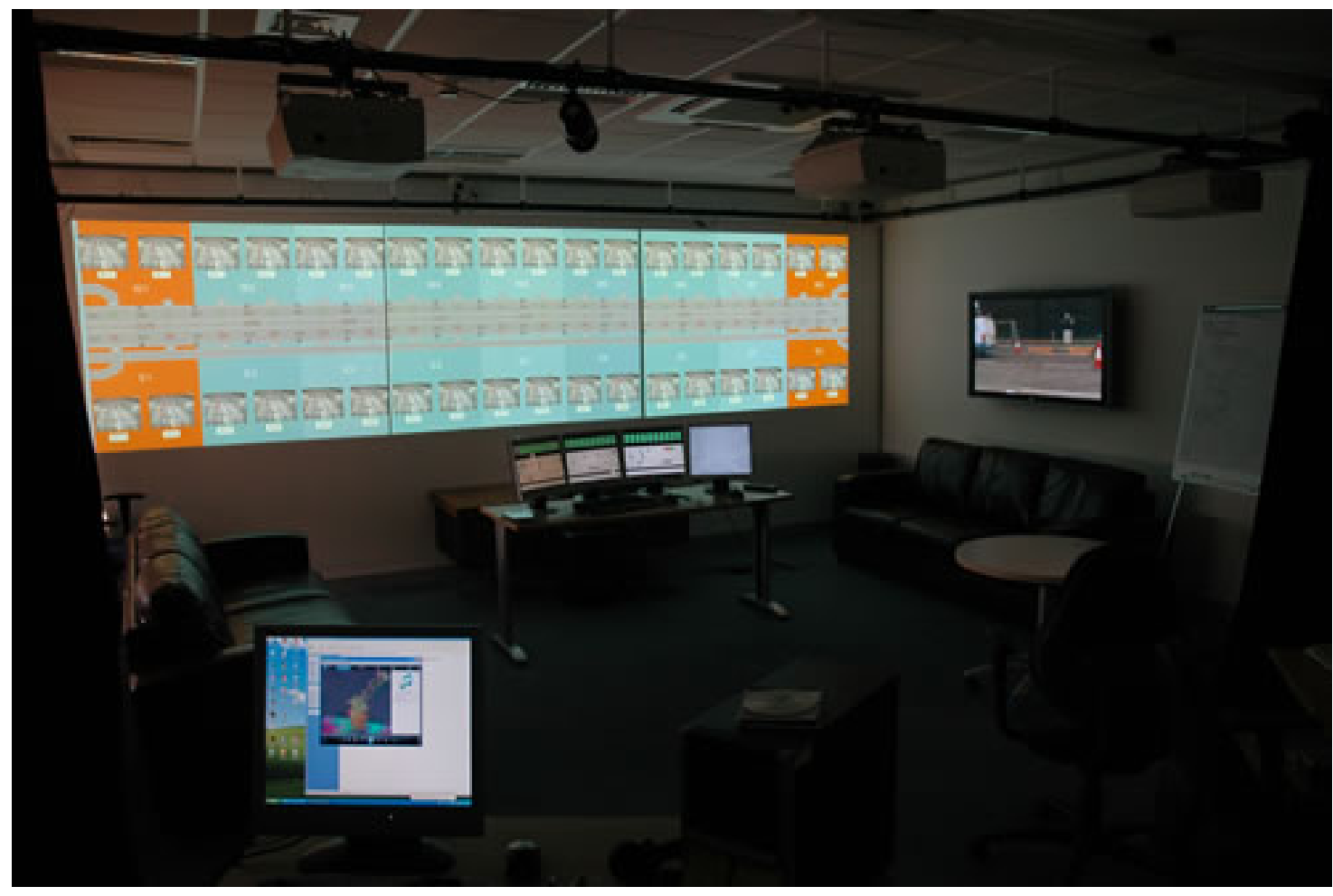

Figure 3. The usability laboratory showing large panel and desktop displays, desktop terminals and simulation control PC (foreground) 


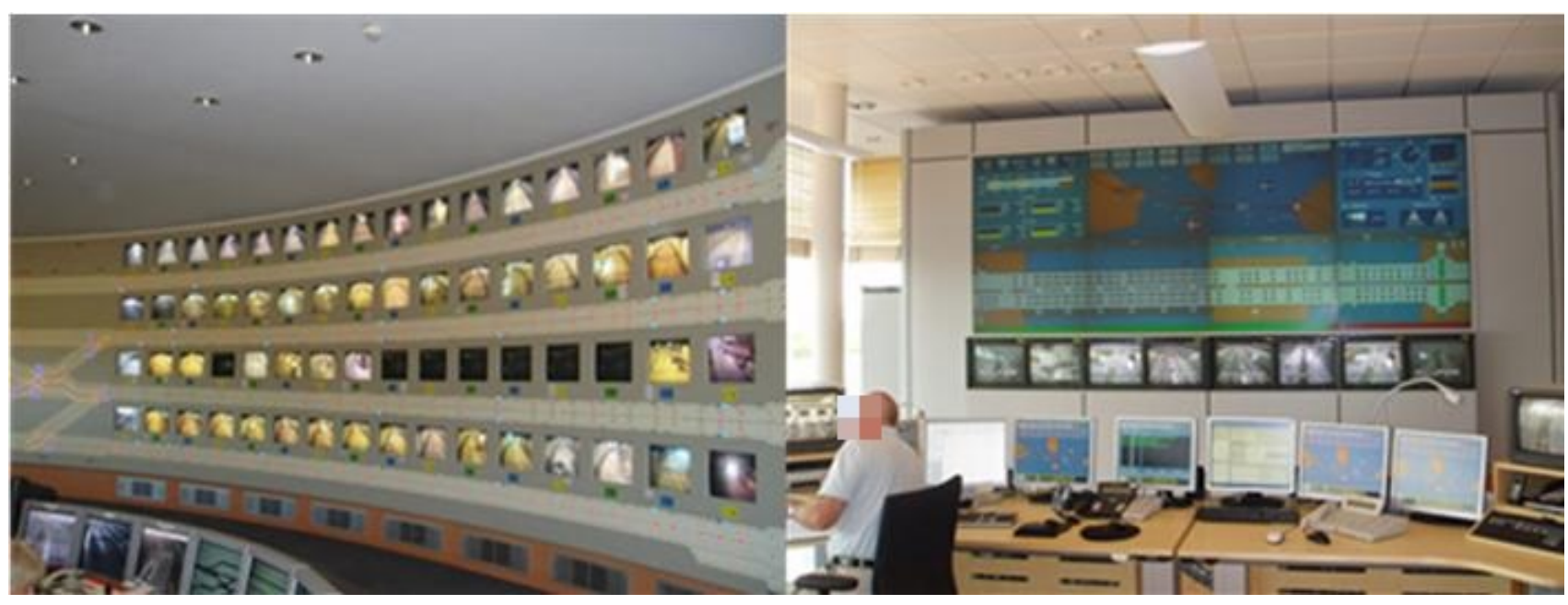

Figure 4. Elbe and Øresund Tunnel control rooms showing tunnel schematic, CCTV images and desktop monitors

Three different simulation environments were created for use at particular stages in the scenariobased evaluation, from the point of view of: the tunnel operator within the tunnel control room (Stages $1 \&$ 2); the fire fighter in an emergency vehicle on route (Stage 3); and the incident commander at the scene of the incident (Stages 4-6). For each stage, the main dynamic information display to the participant was the data on the desktop screens which showed the tunnel-based sensor data.

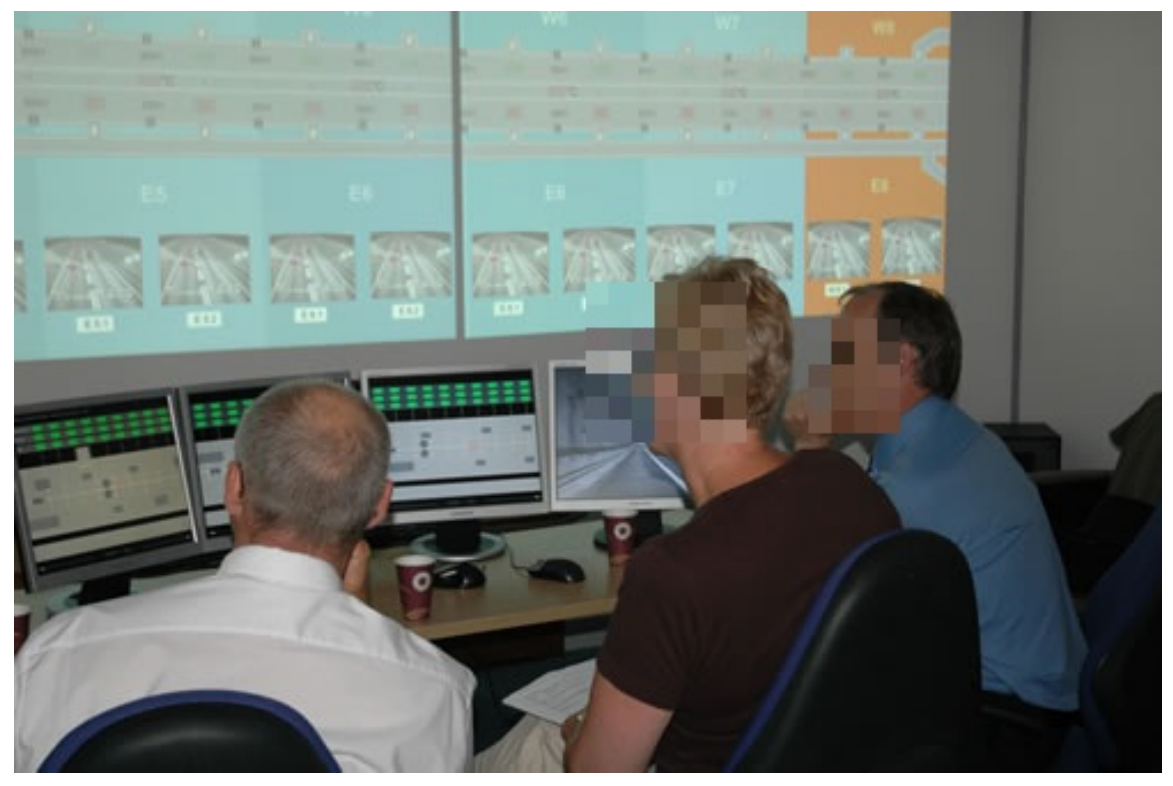

Figure 5. The tunnel control environment during Stage 1 - monitoring hazardous goods during normal operation. Large panel display of layout schematic and CCTV images, desktop simulation of traffic flow and sensor states 


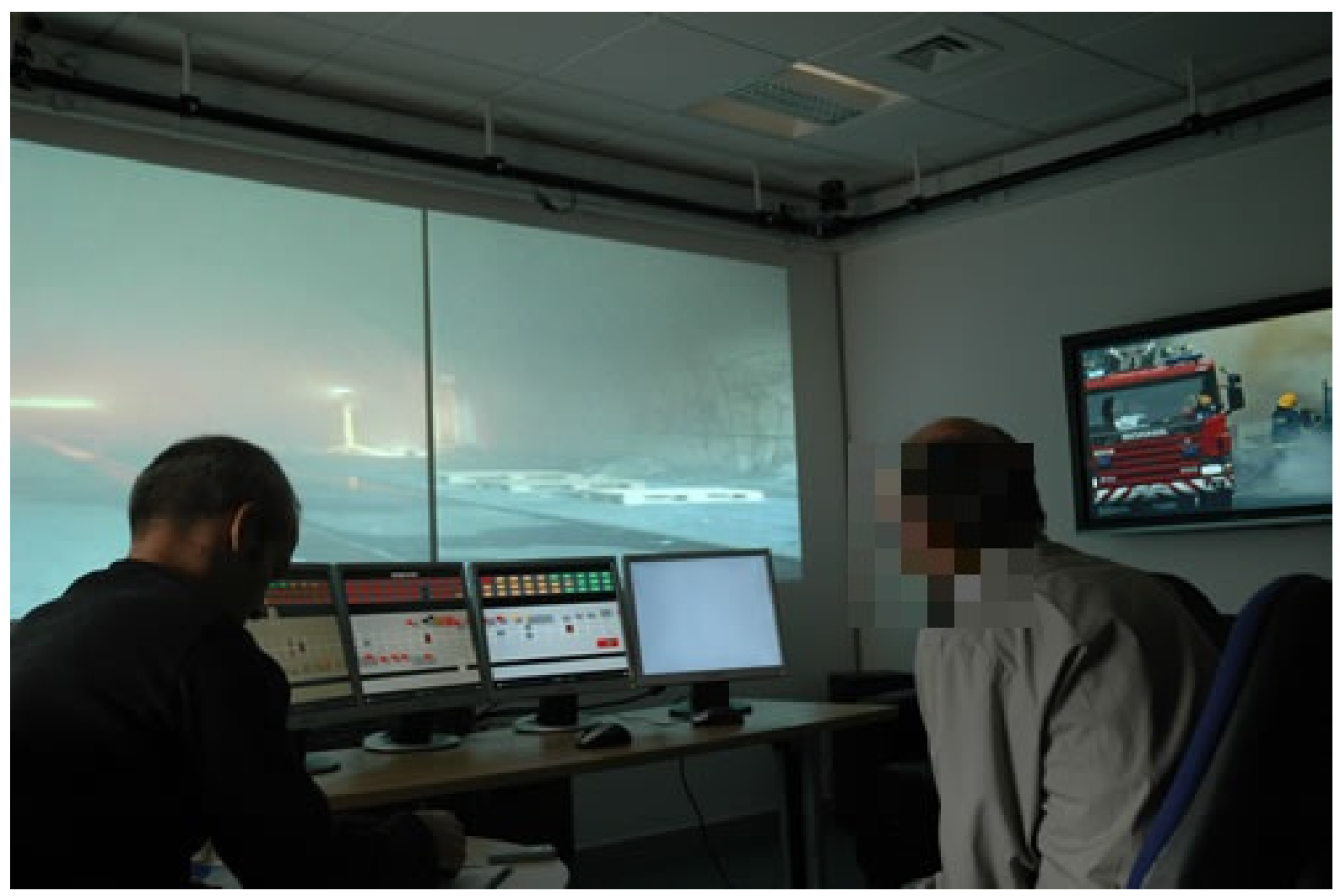

Figure 6. The Incident Commander's viewpoint near the incident location. Large panel display of incident, desktop simulation of traffic and sensor data

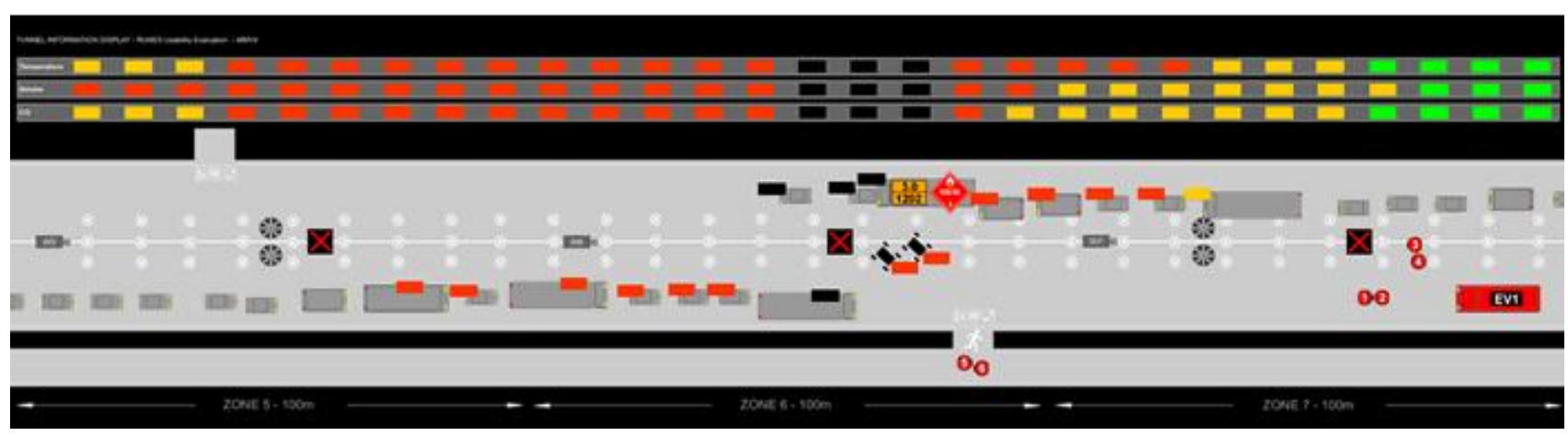

Figure 7. Desktop display during Stage 6, showing tunnel traffic, increased sensor readings and network damage

\subsection{Simulation evaluation participants}

Using the PACT [17] framework, the most relevant people (participants for the study) were defined by the technologies incorporated (WSN), the context (fire-in-tunnel) and the activities (monitoring 
and response, described in each of the scenario stages). The required participants were therefore experts in: IT and WSN (particularly within emergency response), tunnel research and design, and those involved in monitoring and responding to a fire-in-tunnel incident. By specifying the desired participants, and recruiting diversely (including internationally), the study could focus on a relatively small number of highly relevant participants.

Eleven experts took part in the simulation. Of these, eight participated fully in the scenario-based evaluation, and a further three were interviewed after having had the main features demonstrated. The expertise of the participants is described in the Appendix.

\subsection{Data collection}

For each of the scenario stages, detailed rating scale data were collected as shown in Table 3. In all cases judgements were based on a comparison of the advanced WSN version of the scenario compared to the benchmark version of the scenario, and data were collected using a 7-point scale item with the anchors shown below.

\begin{tabular}{|c|c|c|c|}
\hline $\begin{array}{l}\text { Usability } \\
\text { construct }\end{array}$ & Definition & $\begin{array}{l}\text { Level of } \\
\text { measurement }\end{array}$ & Likert scale anchors \\
\hline Effectiveness & $\begin{array}{l}\text { Achieving key } \\
\text { operational objectives }\end{array}$ & $\begin{array}{l}\text { Individual } \\
\text { assessment for each } \\
\text { operational } \\
\text { objective, within a } \\
\text { scenario stage }\end{array}$ & $\begin{array}{l}\text { Much [worse (1) - better } \\
\text { (7)] }\end{array}$ \\
\hline Efficiency & $\begin{array}{l}\text { Time and/or effort } \\
\text { needed to achieve } \\
\text { operational objectives }\end{array}$ & $\begin{array}{l}\text { Overall assessment } \\
\text { for each scenario } \\
\text { stage }\end{array}$ & $\begin{array}{l}\text { Much [more (1) - less } \\
\text { (7)] time and/or effort }\end{array}$ \\
\hline Satisfaction & $\begin{array}{l}\text { Being comfortable } \\
\text { and confident in } \\
\text { meeting operational } \\
\text { objectives }\end{array}$ & $\begin{array}{l}\text { Overall assessment } \\
\text { for each scenario } \\
\text { stage }\end{array}$ & $\begin{array}{l}\text { Much [less (1) - more } \\
\text { (7)] comfortable and } \\
\text { confident }\end{array}$ \\
\hline
\end{tabular}

Table 3. Measurement of usability constructs within the simulation

For each scale assessment, median rating scale values $\tilde{x}$, were calculated from the participant sample; these were aggregated and interpreted as shown in Table 4:

\section{Median value Description}

$\tilde{x}<4 \quad$ WSN 'worse' in relation to [operational objective] 


\begin{tabular}{ll}
\hline $4 \leq \tilde{x}<6$ & $\begin{array}{l}\text { WSN 'equivalent to', or only 'slightly better' in } \\
\text { relation to [operational objective] }\end{array}$ \\
$6 \leq \tilde{x}<7$ & WSN 'better' in relation to [operational objective] \\
$\tilde{x}=7$ & WSN 'much better' in relation to [operational \\
& objective]
\end{tabular}

Table 4. Aggregation and interpretation of Likert Scale data

\subsection{Procedure}

After a welcome and introduction, participants were given a description of the tunnel, control room and incident used within the scenario. Each of the six stages in the scenario was undertaken in turn. Participants were given a list of operational objectives relevant to that stage. Participants viewed the first version of the simulation, which presented information available to them from a standard tunnel environment, including a fixed sensor network installed in the tunnel. They then viewed the second simulation, which comprised the same visual scene, but presented information which could be made available with the WSN. They were then asked to consider each objective in turn and assess the extent to which the advanced networking capabilities enabled them to meet each operational objective (between seven to nine) for each scenario stage. In each case, this was a relative judgement, comparing the two information environments. The subject matter experts were encouraged to replay any aspects of the simulation and discuss the relative benefits and drawbacks of the two different information environments that were simulated - focussing particularly on how the properties of the WSN could impact on their operational response.

\section{Results of simulation}

Stages 1 \& 2 within the simulation (described in Table 2) were undertaken by the tunnel operators only. Stages 3 to 6 were judged by the fire-fighters and fire response experts. The results below show how (in comparison to the benchmark environment) each of the operational objectives relevant to that stage in a fire-in-tunnel incident could be impacted by the WSN. The categorisation of operational objectives for each stage is based on the median responses from participants as set out in Table 4. 


\subsection{Stage 1: Normal tunnel operation}

\section{Benchmark environment}

Normal traffic flow

Data available from a fixed sensor network in the tunnel (temperature, CO, smoke levels)

CCTV visual monitoring of traffic

\section{Advanced WSN environment}

In addition to the benchmark environment:

The transmission of location and hazard data from vehicles in the tunnel

Table 5. Key features of the two versions of Stage 1 of the simulation

WSN 'much better' in relation to: identifying high risk vehicles and cargos before they enter the tunnel; tracking high risk vehicles and cargos as they pass through the tunnel.

WSN 'better' in relation to the following operational objectives: eliminating traffic-related and other false alarms as quickly as possible; identifying and verifying true alarms arising from traffic or technical failure as quickly as possible; preventing illegal or inappropriate tunnel traffic (e.g. cyclists); regulating traffic and provide traffic information during maintenance and poor weather conditions; being comfortable and confident in meeting the operational objectives at this stage in an incident.

WSN 'equivalent to', or only 'slightly better' in relation to: keeping traffic flowing freely; the time and/or effort needed to achieve the operational objectives at this stage in an incident.

\subsection{Stage 2: An incident occurs within the tunnel and fire service alerted}

\section{Benchmark environment}

Data available from a fixed sensor network in the tunnel (temperature, CO, smoke)

CCTV visual monitoring of traffic, which becomes obscured

\section{Advanced WSN environment}

In addition to the benchmark environment:

The transmission of location and HAZMAT data from vehicles in the tunnel

Temperature readings from the vehicles

\section{Table 6. Key features of the two versions of Stage 2 of the simulation}

WSN 'much better' in relation to: confirming that the control room alarm has come from an incident (it is not a false alarm); doing an initial assessment of what has happened and where the incident is; providing the emergency services with the initial information they need about the incident; being comfortable and confident in meeting the operational objectives at this stage in an incident. 
WSN 'better' in relation to: maintaining communications with the emergency services to help them (e.g. barriers, ventilation).

WSN 'equivalent to', or only 'slightly better' in relation to: alerting the emergency services so they can respond; putting into place the procedures \& actions appropriate (e.g. close tunnel, activating warning signs, broadcast evacuation, emergency lights, barriers, traffic signs, ventilation); monitoring the rate of tunnel occupant evacuation; managing road traffic during the incident; informing tunnel, and local and national road/transport management; the time and/or effort needed to achieve the operational objectives at this stage in an incident.

\subsection{Stage 3: Fire crews are sent current dynamic incident information en-route}

\section{Benchmark environment}

Tunnel map sent to the fire crews

Fixed layout only - no data overlaid onto this map

Voice communication giving type of incident, address, approach instructions

\section{Advanced WSN environment}

Live data display in the fire truck

Dynamic temperatures, smoke and CO levels

Locations and temperature readings from vehicles

Voice communications as for benchmark environment

Table 7. Key features of the two versions of Stage 3 of the simulation

WSN 'much better' in relation to: finding out the impact of the incident (e.g. fire temperatures, levels of toxic gases, casualties).

WSN 'better' in relation to: finding out about the incident (e.g. what has happened, where, hazards involved, occupants); formulating an initial response for arrival and mentally rehearsing this; ensuring the necessary resources arrive quickly and safely at the scene; liaising with the other emergency services; the time and/or effort needed to achieve the operational objectives at this stage in an incident; being comfortable and confident in meeting the operational objectives at this stage in an incident.

WSN ‘equivalent to', or only 'slightly better' in relation to: finding out what resources and facilities are available to me when I arrive (e.g. location of water hydrants, other sources, emergency exits); finding out what actions have been taken that will impact on the fire crew safety and/or operational effectiveness. 


\subsection{Stage 4: Fire crews arrive; self-healing of network by switching to wireless data transmission}

\section{Benchmark environment}

Sensor data from the tunnel sensors and vehicle sensors showing smoke, $\mathrm{CO}$ and temperature levels

This data being lost as damage occurs to the network

Lack of information from the tunnel or vehicle sensors once network is damaged

\section{Advanced WSN environment}

Sensor data from the tunnel sensors and vehicle sensors is lost momentarily, but then comes back online

The location and tracking of the arrival in the tunnel of the first fire crew

Table 8. Key features of the two versions of Stage 4 of the simulation

WSN 'much better' in relation to: monitoring temperature, CO, smoke levels and fire spread, and their rate of change; doing an overall situation assessment of the incident; determining if there are any immediate risks to the fire crew and maximise their safety; monitoring and directing fire crew positioning and the actions they are taking; assessing impact of future risks that may arise; deciding what my next steps need to be; the time and/or effort needed to achieve the operational objectives at this stage in an incident; being comfortable and confident in meeting the operational objectives at this stage in an incident.

WSN 'better' in relation to: determining how well my current fire fighting strategy is working; liaising with the other emergency services.

WSN 'equivalent to', or only 'slightly better' in relation to: identifying and using physical resources (e.g. hydrants, emergency exits).

4.5 Stage 5: Fire damage increases, and self-healing of network by re-routing of wireless sensor data

\section{Benchmark environment}

Sensor data from the tunnel sensors and vehicle sensors showing smoke, $\mathrm{CO}$ and temperature levels

Tracking of fire fighter movements and ambient temperatures

Loss of this tunnel and fire-fighter data when damage occurs

\section{Advanced WSN environment}

Sensor data from the tunnel sensors, vehicle sensors, and fire-fighters is lost momentarily, but then maintained as damage to the network occurs

(Data is eventually lost when damage is too great)

Table 9. Key features of the two versions of Stage 5 of the simulation 
WSN 'much better' in relation to: monitoring temperature, CO, smoke levels and fire spread, and their rate of change; doing an overall situation assessment of the incident; determining if there are any immediate risks to the fire crew and maximise their safety; monitoring and directing fire crew positioning and the actions they are taking; assessing impact of future risks that may arise; deciding what my next steps need to be; the time and/or effort needed to achieve the operational objectives at this stage in an incident; being comfortable and confident in meeting the operational objectives at this stage in an incident.

WSN 'better' in relation to: identifying and using physical resources; determining how well my current fire fighting strategy is working; liaising with the other emergency services.

\subsection{Stage 6: Restoration of connectivity using self-positioning robot-mounted sensors}

\section{Benchmark environment}

Zero data from the part of the network that has been damaged, no information on the firefighters or vehicles
Advanced WSN environment

Information still available on the tunnel temperatures, $\mathrm{CO}$ and smoke levels, vehicle temperatures, location of the fire fighters

\section{Table 10. Key features of the two versions of Stage 6 of the simulation}

WSN 'much better' in relation to: assessing impact of future risks that may arise; deciding what my next steps need to be.

WSN 'better' in relation to: monitoring temperature, $\mathrm{CO}$, smoke levels and fire spread, and their rate of change; doing an overall situation assessment of the incident; determining if there are any immediate risks to the fire crew and maximise their safety; monitoring and directing fire crew positioning and the actions they are taking; determining how well my current fire fighting strategy is working; liaising with the other emergency services; the time and/or effort needed to achieve the operational objectives at this stage in an incident; being comfortable and confident in meeting the operational objectives at this stage in an incident.

WSN 'equivalent to', or only 'slightly better' in relation to: identifying and using physical resources. 


\section{Discussion}

The specific contribution of this paper is twofold. Firstly, it demonstrates a link between the enabling properties of WSN and the operational benefits for emergency response. Most previous work on WSN within this field has either focussed on technical aspects such as algorithms, architectures, and protocols, or information requirements and human performance. Although some recent studies have specifically addressed ER technology from a user-centred perspective (e.g. [45]), these have tended to focus on interfaces, rather than the underlying capabilities that the technology provides. The second contribution to the fire safety literature is methodological - to introduce a means of designing and evaluating a 'future world' [44] linked to emerging technologies. Although established within the UCD field, in the experience of the authors, this has not been seen within emergency management.

As the WSN is enhancing the information environment available to the emergency responders, its value over existing networks and infrastructure occurs, as might be expected, when the operational requirements are related to information gathering and decision making activities. During the normal operational phase, organisations are undertaking data gathering and assessment [46]. When an incident occurs, the emergency response team must confirm the nature of the incident, and this is when a WSN can start to provide more detail than is typically available within a tunnel, including information on hazards from individual vehicles.

During the later command and control phases of an incident, the emergency response team must monitor conditions and assess the effectiveness of the actions being undertaken [46]. WSNs offer relative advantage at these stages due to the ability to maintain a degree of information flow from the tunnel despite potential damage to the tunnel infrastructure. This is the reduction in the degradation of the information environment exemplified in Figure 1. This enhances all three levels of SA [20] i.e. identification of elements in the environment, interpretation of their meaning, and their future projection. In particular, WSNs can maintain the context, casualty and resources information described by Yang et al. [47]. This enables the adaptation of the fire fighting response in order to maximise its effectiveness within a given situation. In relation to specific operational goals, configurable networks added value over and above current sources of information, e.g. visual inspection (which may be difficult in a tunnel environment) and CCTV which is likely to be obscured through smoke [48]. Results of the simulation show that WSNs provide less value where information relates to assets comprising static data values - such as plans of the tunnel infrastructure - since this does not need mobile or dynamic data acquisition. 
It was clear that the real time savings (i.e. the efficiency usability component) related to enhancement of SA [13] would come from providing information that was not otherwise available, rather than just providing more information because it was technologically feasible. As noted by Prasanna et al. [49], much previous work in emergency response has focussed on the generation of information, rather than the usefulness of this in relation to the emergency response operational goals. During the early stages of the simulated incident, there was concern from the tunnel operators that although they may be more confident in their decision making, the additional information provided to them may require spending more time and effort assimilating this information. One fire commander underlined the need to 'do something' (i.e. be operational) rather than spending too much time assimilating information and making decisions, this is in line with the naturalistic form of decision making that is typically undertaken by experienced personnel within emergency response [50].

During all stages of the simulation, the WSN was judged as increasing the comfort and confidence (third usability component) of the tunnel operators and incident commanders when tackling their operational objectives. Information provided while the response team are en-route can help in physical and mental preparation for arrival [49]. Interestingly, this increased confidence due to more accurate and timely information can result in more appropriate decisions, rather than the safest decisions - the change in the decision making attitude of the end user noted by Prasanna et al. [49]. In addition to the expert assessments against specific operational objectives, the simulations allowed a detailed discussion with the subject matter experts of the wider opportunities (including situation assessment) that WSNs provide for enhancing a fire-in-tunnel emergency response. There are specific opportunities where information during a fire-in-tunnel incident is currently not possible or difficult to access, including: information on hazardous loads; tracking of fire crew within an incident in order to direct their response and aid casualty search and rescue; better estimations of the number of casualties involved in major incidents; and providing information about or to vulnerable groups who may not be able to self-rescue during an incident. Several opportunities arise from being able to integrate and fuse data from a variety of sources, in order to reduce cognitive demand on the fire commander - for example integration of fire crew location with incident data in order to assess the potential risks. This includes interoperability with legacy systems, or systems using different communication or encryption protocols. There was also potential to reduce unnecessary voice communication (and the concomitant demands on short-term memory [49] through data-driven enhancement of SA, and also easier maintenance of an incident history, to enable a longer term assessment of the damage to the infrastructure, and for post-event evaluation of the response. 
Two main concerns were expressed by both tunnel operators and incident commanders. The first was the need to specifically focus on supporting the operational emergency response, and to add value over and above what was currently available, e.g. the use of CCTV for monitoring traffic. There should be a focus on providing meaning in relation to a specific operational objective (e.g. Level 2 SA), rather than just providing data. There was also concern over potential information overload, and the need to both prioritise information, and match the level of detail of information supplied to the specific needs of the individual. The second main issue was the potential reliability of the technology, and trust in the systems, an issue well documented as influencing the impact of technology in safety-critical systems [51]. A fire-in-tunnel is a challenging operational environment for a WSN. The tunnel infrastructure itself has been shown to increase data loss to approximately three times the levels of outdoor environments [52]. However, the tests carried out by [53] concluded that showed that ultrasound, infrared and radio sensors can be deployed in a firefighting environment, and that within their test regime, '2.4GHz signals are not affected by smoke and heat'. If data was lost, then maintenance of last known data was necessary. In addition, notification of failure modes was important to identify whether lost data was due to wider scale network failure, or more localised damage to sensors. Security, authentication and access (particularly with a multiagency emergency response) were vital, in line with Yang et al. [8].

The main aim of the simulation was a formative judgement [54] of the potential impact of a WSN. However, an unexpected outcome was the stated value of the simulation for promoting potential buy-in by emergency response stakeholders. The concepts of new data provision enabled by advanced networks can be difficult to explain to end users since they are not tangible products. A realistic simulation, that also includes the important aspects of the working environment (e.g. simulates a noisy environment), is a valuable and low cost tool for demonstrating the benefits that new networks provide to end users who are focussed on achieving specific work goals.

The specific focus of the study was the 'alternative world' view in relation to WSN in fire-in-tunnel emergency response. The study made an explicit comparison of operational objectives between the benchmark and advanced WSN environments shown in Sections 4.1 to 4.6, and hence the results are a direct outcome from the design of this simulation and experiment. Accordingly, the participant group was chosen to provide expertise in relation to this specific simulation. However, many of the operational objectives (Section 4) are generic ER response goals, and the impact is discussed above in terms of the impact on different levels of SA [20], at different phases generic within fire monitoring and response, and the established usability outcomes of effectiveness, efficiency and confidence. 


\section{Conclusions}

This paper makes a link between the enabling properties of new technology and the potential impact on operational objectives. The paper also exemplifies a method for designing, communicating and testing a 'future world' view. Various properties of advanced WSN networks were demonstrated to subject matter experts in a relatively low-cost manner: collecting data from fixed and mobile assets; providing data to fixed and mobile locations; integrating data from a variety of sources; and maintaining data when damage to network and sensors occurs. These properties were shown to provide operational benefits including improved SA. In addition, the use of a detailed multi-media simulation with subject matter experts was shown to be useful for promoting buy-in of new technologies where resistance to change has been noted. However the over-riding message from the subject matter experts was the need to take a user-centred, rather than technological perspective, and to provide the right information [55], not just more information, at the point of need.

\section{Acknowledgements}

The authors wish to thank the partners in the European Union RUNES project (IST-004536), and the funding contribution made by Kodak European Research.

\section{References}

[1] M. R. Endsley, C. a. Bolstad, D. G. Jones, and J. M. Riley, “Situation Awareness Oriented Design: From User’s Cognitive Requirements to Creating Effective Supporting Technologies,” Proc. Hum. Factors Ergon. Soc. Annu. Meet., vol. 47, no. 3, pp. 268-272, Oct. 2003.

[2] J. R. Lawson and R. L. Vettori, “Federal Building and Fire Safety Investigation of the World Trade Center Disaster: The Emergency Response Operations,” 2005.

[3] S. H. Yang and P. Frederick, "SafetyNET: a Wireless Sensor Network for Fire Protection and Emergency Responses,” Measurment+Control, vol. 39, no. 7, pp. 218-219, 2004.

[4] R. Bogue, “Sensors for fire detection,” Sens. Rev., vol. 33, no. 2, pp. 99-103, 2013. 
[5] X. Li, Z. Ji, H. Zhu, and C. Gu, “A feasibility study of the measuring accuracy and capability of wireless sensor networks in tunnel monitoring,” Front. Struct. Civ. Eng., vol. 6, no. 2, pp. 111-120, May 2012.

[6] N. A. A. Aziz and K. A. Aziz, “Managing Disaster with Wireless Sensor Networks,” in 13th International Conference on Advanced Communication Technology (ICACT),, 2011, no. December 2008, pp. 202-207.

[7] Y. Yang, R. Prasanna, L. Yang, and A. May, “Opportunities for WSN for facilitating fire emergency response,” in 5th International Conference on Information and Automation for Sustainability (ICIAFs), 2010, pp. 81-86.

[8] L. Yang, R. Prasanna, and M. King, “On-site information systems design for emergency first responders,” J. Inf. Technol. Theory Appl., vol. 10, no. 1, pp. 5-27, 2009.

[9] K. Sha, W. Shi, and O. Watkins, "Using Wireless Sensor Networks for Fire Rescue Applications : Requirements and Challenges," in IEEE International Conference on Electro/information technology, 2006, pp. 239-244.

[10] F. Bergstrand and J. Landgren, "Information sharing using live video in emergency response work,” in Proceeding of the 6th International ISCRAM Conference, 2009, no. May.

[11] J. Woodhall, “The Future of Emergency Response: Need for Technology Enabled Process Transformation,” in Proceedings of National Science Foundation Conference: Educational Programs for Emergency Response Technology, 2007.

[12] L. Norros, R. Hutton, P. Grommes, N. Colford, P. Savioja, and M. Liinasuo, “Analysis of work demands of multi-agency emergency response activity for developing information support systems," in European Conference on Cognitive Ergonomics: Designing beyond the Product---Understanding Activity and User Experience in Ubiquitous Environments, 2009, pp. 2-6.

[13] M. R. Endsley, B. Bolte, and D. G. Jones, Designing for Situation Awareness: An Approach to User-Centered Design. Taylor \& Francis, 2003. 
[14] R. Prasanna, “Information Systems for Supporting Fire Emergency Response,” PhD Thesis, Loughborough University, 2010.

[15] L. Carver and M. Turoff, "Human-Computer Interaction: The Human and the Computer as a Team in Emergency Management Information Systems,” Commun. ACM, vol. 50, no. 3, pp. 33-38, 2007.

[16] J. Gulliksen, B. Göransson, I. Boivie, S. Blomkvist, J. Persson, and Å. Cajander, “Key principles for user-centred systems design,” Behav. Inf. Technol., vol. 22, no. 6, pp. 397-409, Nov. 2003.

[17] D. Benyon and C. Macaulay, "Scenarios and the HCI-SE design problem,” Interact. Comput., vol. 14, no. 4, pp. 397-405, Jul. 2002.

[18] D. J. Bryant, "Making Naturalistic Decision Making ' Fast and Frugal ',” in Proceedings of the 7th International Command and Control Research and Technology Syposium, 2002.

[19] S. M. George, W. Zhou, H. Chenji, M. Won, Y. O. Lee, A. Pazarloglou, R. Stoleru, and P. Barooah, "DistressNet : A Wireless Ad Hoc and Sensor Network Architecture for Situation Management in Disaster Response,” Commun. Mag. IEEE, vol. 48, no. 3, pp. 128-136, 2010.

[20] M. R. Endsley, “Toward a theory of situation awareness in dynamic systems,” Hum. Factors, vol. 37, no. 1, pp. 32-64, 1995.

[21] M. Endsley and E. Connors, "Situation awareness: State of the art," in Proceedings of Power and Energy Society General Meeting: Conversion and Delivery of Electrical Energy in the 21st Century, 2008, pp. 1-4.

[22] B. Van De Walle and M. Turoff, "Communications of the acm,” Commun. ACM, vol. 50, no. 3, pp. 29-31, 2007.

[23] J. Son, Z. Aziz, and F. Peña-Mora, “Supporting disaster response and recovery through improved situation awareness,” Struct. Surv., vol. 26, no. 5, pp. 411-425, 2007.

[24] J. Son and F. Peña-Mora, “Improvement of Collaboration among First Responders including Civil Engineers during Disaster Response in Urban Areas,” in Joint Interntional Conference on Computing and Decision Making in Civil and Building Engineering, 2006, pp. 2447-2456. 
[25] S. Mitra, A. De Sarkar, and S. Roy, “A review of fault management system in wireless sensor network," in Proceedings of the CUBE International Information Technology Conference on CUBE '12 ACM New York, 2012, pp. 144-148.

[26] A. Ahmed and L. Sugianto, "What Benefits Can Be Brought Forward by Adopting RFID in Emergency Management?," in Proceedings of Second International Conference on Engineering Systems Management and Its Applications (ICESMA), 2010, pp. 1-6.

[27] F. Oldewurtel, J. Riihijarvi, K. Rerkrai, and P. Mahonen, “The RUNES Architecture for Reconfigurable Embedded and Sensor Networks,” in 2009 Third International Conference on Sensor Technologies and Applications, 2009, pp. 109-116.

[28] H. Will, T. Hillebrandt, and M. Kyas, "Wireless Sensor Networks in Emergency Scenarios : The FeuerWhere Deployment,” in In Proceedings of the 1st ACM international workshop on Sensor-Enhanced Safety and Security in Public Spaces, 2012, pp. 9-14.

[29] E. Gelenbe and G. Gorbil, "Wireless networks in emergency management," Proc. first ACM Int. Work. Pract. issues Appl. next Gener. Wirel. networks - PINGEN ’12, pp. 1-6, 2012.

[30] S. Chaudhury, "Disaster management using mobile robots," in Proceedings of the 1st International Conference on Wireless Technologies for Humanitarian Relief (ACWR '11). ACM, New York, 2011, p. 108.

[31] ISO, “ISO 13407: Human-centred design processes for interactive systems,” International Standards Organisation, Geneva, 1999.

[32] A. J. May, "Using a 'value-added' approach for contextual design of geographic information,” Appl. Ergon., vol. Available, 2012.

[33] N. Ahituv, S. Neumann, and H. N. Riley, Principles of information systems for management, vol. 4th. Dubuque IA: W.C. Brown, 1994.

[34] N. a Stanton, "Hierarchical task analysis: developments, applications, and extensions.,” Appl. Ergon., vol. 37, no. 1, pp. 55-79, Jan. 2006. 
[35] D. L. Phipps, G. H. Meakin, and P. C. W. Beatty, "Extending hierarchical task analysis to identify cognitive demands and information design requirements.,” Appl. Ergon., vol. 42, no. 5, pp. 741-8, Jul. 2011.

[36] R. Prasanna, L. Yang, and M. King, “GDIA: a Cognitive Task Analysis Protocol to Capture the Information Requirements of Emergency First Responders,” in Proceedings of the 6th International ISCRAM Conference, 2009, no. May 2009.

[37] ISO, “BS EN ISO 9241-11:1998 Ergonomics requirements for office work with visual display terminals (VDTs): Guidance on specifying and measuring usability,” International Standards Organisation, Geneva, 1998.

[38] N. Bevan, “International standards for HCI and usability,” Int. J. Hum. Comput. Stud., vol. 55, pp. 533-552, 2001.

[39] M. Endsley, “Designing for situation awareness in complex systems,” in Proceedigs of the Second International Workshop on symbiosis of humans, artifacts and environment, 2001.

[40] M. . Endsley and D. . Garland, Situation Awareness Analysis and Measurement. Mahwah, NJ: Lawrence Erlbaum Associates, 2000.

[41] J. M. Carroll, Making Use: Scenario - based Design of Human - Computer Interactions. Cambridge, Massachusetts,: The MIT Press., 2000.

[42] J. M. Carroll, Ed., Scenario-based Design: Envisioning Work and Technology in System Development. John Wiley \& Sons Inc, 1995.

[43] I. F. Alexander and N. Maiden, Scenarios, stories, use cases through the systems development life-cycle. John Wiley \& Sons, 2004, p. 520.

[44] D. Bush, “Alternative world scenarios to assess requirement stability,” in in Scenarios, Stories, Use Cases, I. Alexander and N. Maiden, Eds. John Wiley \& Sons Ltd, 2004, pp. 103117.

[45] R. Prasanna, L. Yang, and M. King, "Guidance for developing human-computer interfaces for supporting fire emergency response,” Risk Manag., vol. 15, no. 3, pp. 155-179, Aug. 2013. 
[46] M. Jennex, “Modeling emergency response systems,” in 40th Hawaii International Conference on System Sciences, 2007., 2007, pp. 1-8.

[47] L. Yang, R. Prasanna, and M. King, "Situation Awareness Oriented User Interface Design for Fire ER,” J. Emerg. Manag., vol. 7, no. 2, pp. 65-74, 2009.

[48] A. May, V. Mitchell, J. Piper, L. Hanna, S. Hailes, and K. Koumpis, “Opportunities and Challenges for Configurable Sensor Networks for Enabling Effective Fire-In-Tunnel Response,” in The International Emergency Management Society 14th TIEMS Annual Conference 2007, 2007, vol. Trogir, Cr, pp. 457-466.

[49] R. Prasanna, M. King, and L. Yang, “Guidance for Developing Human Computer Interfaces for Supporting Fire Emergency Response,” Risk Manag. (to Appear.

[50] G. Klein, “The recognition-primed decision (RPD) model: Looking back, looking forward.,” in in Naturalistic decision making. Expertise: Research and applications, G. Klein and C. E. Zsambok, Eds. Hillsdale, NJ, England: Lawrence Erlbaum Associates, 1997, pp. 285-292.

[51] M. Grabowski and S. D. Sanborn, "Human performance and embedded intelligent technology in safety-critical systems,” Int. J. Hum. Comput. Stud., vol. 58, no. 6, pp. 637-670, Jun. 2003.

[52] X. Li, Z. Ji, H. Zhu, and C. Gu, “A feasibility study of the measuring accuracy and capability of wireless sensor networks in tunnel monitoring,” Front. Struct. Civ. Eng., vol. 6, no. 2, pp. 111-120, 2012.

[53] E. Schubert and M. Scholz, "Evaluation of wireless sensor technologies in a firefighting environment,” 2010 Seventh Int. Conf. Networked Sens. Syst., pp. 157-160, Jun. 2010.

[54] S. Makri, A. Blandford, A. L. Cox, S. Attfield, and C. Warwick, "Evaluating the Information Behaviour methods: Formative evaluations of two methods for assessing the functionality and usability of electronic information resources,” Int. J. Hum. Comput. Stud., vol. 69, no. 7-8, pp. 455-482, Jul. 2011.

[55] J. M. Flach, K. J. Vicente, F. Tanabe, K. Monta, and J. Rasmussen, “An Ecological Approach to Interface Design,” in Human-System Interaction: The Sky’s No Limit. Human Factors and Ergonomics Society 42nd Annual Meeting, Chicago, Illinois, 1998, vol. 1, no. -, pp. 295-299. 
[56] A. Qandour, D. Habibi, and I. Ahmad, "Wireless sensor networks for fire emergency and gas detection,” in Proceedings of 2012 9th IEEE International Conference on Networking, Sensing and Control, 2012, pp. 250-255.

\section{Appendix - Simulation participant details}

\begin{tabular}{|c|c|c|c|}
\hline Position & Organisation & Country & Participation \\
\hline $\begin{array}{l}\text { Fire Commander and } \\
\text { Independent Fire Safety } \\
\text { Engineer }\end{array}$ & $\begin{array}{l}\text { City fire service, large road } \\
\text { tunnel }\end{array}$ & Germany & Simulation \\
\hline $\begin{array}{l}\text { Fire Simulation Suite } \\
\text { Manager }\end{array}$ & Fire training college & UK & Simulation \\
\hline Secretary & $\begin{array}{l}\text { EU fire officer trade } \\
\text { association }\end{array}$ & Netherlands & Interview \\
\hline Operations Manager & $\begin{array}{l}\text { Regional fire \& rescue } \\
\text { service }\end{array}$ & UK & Simulation \\
\hline $\begin{array}{l}\text { Health \& Safety } \\
\text { Manager }\end{array}$ & Large road tunnel & Denmark & Simulation \\
\hline Operations Manager & Large road Tunnel & Denmark & Simulation \\
\hline $\begin{array}{l}\text { Remote systems and } \\
\text { power equipment }\end{array}$ & Tunnel research centre & France & Interview \\
\hline $\begin{array}{l}\text { Technical Director } \\
\text { Operational Fire Fighter }\end{array}$ & $\begin{array}{l}\text { Consultancy and } \\
\text { regional fire \& rescue service }\end{array}$ & UK & Simulation \\
\hline Technical Advisor & Road authority agency & UK & Simulation \\
\hline $\begin{array}{l}\text { Head of IT and } \\
\text { Software Development }\end{array}$ & $\begin{array}{l}\text { Systems design house and } \\
\text { U2010 Project member }\end{array}$ & Luxembourg & Simulation \\
\hline $\begin{array}{l}\text { Chief Contingency } \\
\text { Officer }\end{array}$ & Regional police force & UK & Interview \\
\hline
\end{tabular}

